\title{
Are we willing to build a better future?
}

\author{
Valentí Rull \\ Botanic Institute of Barcelona (IBB-CSIC-ICUB) \\ Pg. del Migdia s/n, 08038 Barcelona, Spain \\ phone +34 93 2890611, fax +34 2890614 \\ E-mail: vrull@ibb.csic.es
}

Post-print revised and accepted by Elsevier

Trends in Ecology \& Evolution, Volume 28, Issue 8, 443-444, 22 May 2013 
Nekola et al. [1] contend that Malthusian limits and Darwinian innovation are two major forces in population dynamics, and that their interplay is central to determine whether humans will be able to establish sustainable relationships with the finite Earth. According to these authors, two crucial questions are: what are the growth limits? and, what if they are met? Nekola et al. also propose three strategies for a sustainable future: “(i) negative population growth for a number of generations, followed by zero growth; (ii) a steady-state economy based on sustainable use of renewable energy and material resources; and (iii) new social norms that favour the welfare of the entire global population over that of specific individuals and groups”. The authors largely rely on biological and/or cultural evolution to attain such goals.

The Nekola et al. concerns have already been addressed and much more information is available for discussion; their paper may produce the wrong impression that the topic is much less developed that it actually is and that their proposals are original. These authors also fail to explain why future evolution should necessarily lead to more sustainable practices.

The issue of the limits for human growth on Earth was recently analysed in depth in a keystone paper by Rockström et al. [2], who defined nine critical planetary boundaries. Quantitative estimates for seven of these limits $\left(\mathrm{CO}_{2}\right.$ atmospheric concentration, ocean acidification, stratospheric ozone, biogeochemical nitrogen and phosphorus cycles, freshwater use, land system change and rates of biodiversity loss) were provided. The other two, chemical pollution and atmospheric aerosol loading, could not be quantified. According to these authors, three of these boundaries have been already transgressed, namely the rates of climate change and biodiversity loss, and changes in the global nitrogen cycle. Another limit that would have been already 
crossed is land use, as the terrestrial biosphere made the critical transition from mostly wild to mostly anthropogenic early in the $20^{\text {th }}$ century [3].

Population control has been also widely treated. For example, a number of researchers believe that a new and global 'green revolution' is the solution to sustain the prognosticated increase in human population for the middle of this century [4]; however, this would only aggravate the situation without the corresponding population controls [5]. With or without 'green revolution' population control seems to be critical for a safe future [6].

The need for negative growth has been extensively considered under the name of ‘degrowth’ [7], a particularly active field of research with the involvement of a wide range of professional interests including economy, ecology, sociology, law, philosophy and many others, who are organised in the 'Research \& Degrowth' academic society (www.degrowth.eu). Degrowth defenders believe that human progress is possible without economic growth and suggest that a balanced decline of both production and consumption can promote human welfare and improve ecological conditions both locally and globally, in the short and long term [7]. This movement is also well structured from a practical perspective, with concrete proposals and working programs aimed at a profound societal transformation [8]. Steady-state economy has been also widely considered, primarily from an economical angle [9].

The urgent need for new social norms leading to global social justice has been equally evaluated and is now a vividly debated issue. The options are varied, ranging from adaptation proposals avoiding open confrontation with the currently dominant socio-economic system to frontal opposition to global capitalism $[6,10]$. Intermediate solutions, as for example the selective use of particular economic tools to deal with the 'commons', have been also envisaged [11]. 
The Nekola et al. claim that "humanity has not yet evolved the genetic or cultural adaptations needed to accomplish these tasks” is teleological as it implicitly assumes that humans are ultimately called to be in harmony with nature and we will evolve in such direction. This belief seems to have its roots in the Judaeo-Christian tradition of human 'destiny', rather than on the available scientific evidence showing that evolution is non-directional, contingent and unpredictable [12]. On the other hand, evolution has already provided the tools to be aware of the situation, to envisage potential solutions and to make the corresponding decisions. The question is whether we are willing to use these tools to assure a better future. 


\section{References}

1. Nekola, J.C. et al. (2013) The Malthusian-Darwinian dynamic and the trajectory of civilization. Trends Ecol. Evol. 28, 127-130

2. Rockström, J. et al. (2009) Planetary boundaries: exploring the safe operating space for Humanity. Ecol. Soc. 14 (http://www.ecologyandsociety.org/vol14/iss2/art32/)

3. Ellis, E.C. et al. (2010). Anthropogenic transformation of the biomes, 1700 to 2000. Glob. Ecol. Biogeogr. 19, 589-606

4. Beddington, J. (2010) Food security. Contributions from science to a new greener revolution. Phil. Trans. R. Soc. Lond. B Biol. Sci. 365, 61-71

5. Rull, V. (2010). Food security: green revolution drawbacks. Science 328, 169

6. Ehrlich, P. \& Ehrlich, A.H. (2013) Can a collapse of global civilization be avoided? Proc. R. Soc. B 280, 20122845

7. Schneider, F. et al. (2010) Crisis or opportuniy? Economic degrowth for social equity and ecological sustainability. J. Clean Prod. 18, 511-518

8. Martinez-Alier, J. et al. (2010) Sustainable de-growth: mapping the context, criticisms and future prospects of an emergent paradigma. Ecol. Econ. 69, 17411747

9. Lawn, P. (2010) Facilitating the transition to a steady-state economy: some macroeconomic fundamentals. Ecol. Econ. 69, 931-936

10. Rull, V. (2011) Sustainability, capitalism and evolution. EMBO Rep. 12, 103-106

11. Costanza, R. (2009) Could climate change capitalism? Nature 458, 1107-1108 12. Mayr, E. (2004) What makes biology unique? Cambridge University Press 